\title{
An Intertextual Perspective of Chinese Dream and American Dream
}

\author{
Yingjie Guo ${ }^{1}$ and Qing Zhao ${ }^{2}$ \\ ${ }^{1}$ School of Foreign Languages, Shaanxi Normal University, Xi'an 710062, China \\ ${ }^{2}$ School of Foreign Languages, Xi'an University of Finance and Economics, Xi'an 710100, China \\ guoyingjie@snnu.edu.cn, bluehaddylight@163.com
}

\begin{abstract}
To have an intertextual perspective of Chinese Dream and American Dream, the paper employs Julia Kristeva's concept of intertextuality and probes into their corresponding historical backgrounds for the consideration of their cultural roots and unique developments. Obviously, the two dreams are deeply rooted in their own respective traditions and cultures which characterize themselves with intertextual traces, either interweaving or echoing. Additionally, there are more evidences to demonstrate that the two dreams are intrinsically intertextual through observing and examining their common pursuits that necessarily but not comprehensively include (1) the prosperity of the nation, (2) the happiness of the people, (3) the harmony of the society and (4) the peace of the world. Finally, the paper summarizes that the intertextual relationship of Chinese Dream and American Dream needs further argumentation by referring to the budding research progress while the research perspectives should be diversified at home and abroad in the future.
\end{abstract}

Index Terms - American Dream, Chinese Dream, Intertextual.

\section{Introduction}

Speaking of dreams, we have to confess that all human beings, either rich or poor, old or young, tall or short, may have dreams and the dreams may be ambitious or humble, entertaining or depressive, gorgeous or horrible while they come sensible not only for Chinese people but also for American people[1]. Also, it is well recognized that some human dreams are comparatively easy to realize while some may never come true. However, though dreams seem magic in form, they can be traced back to realities and seen through realities. According to Sigmund Freud (1856-1939), founding father of world psychoanalysis, dreams will associate the unconscious and the "libido, an energy with which mental processes and structures are invested and which generates erotic attachments"[2] by viewing man's "tendency toward survival, propagation, sex, and other creative, life-producing drives"[3]. Meanwhile, dreams can be examined through the perspective of intertextuality because human dreams will be an indispensable part of the known "text". Based on Julia Kristeva (1941- ) and her essay "Word, Dialogue and Novel", a text, if we explore in a specific way, may refer to a literary and linguistic form in a language, or a philosophical and cultural form in a society. Besides, it will imply an obvious and concrete existence of a thing like a story or a poem, and it can also relate to an invisible and abstract state of a being like a dream or an imagination. Yet essentially, "Any text is constructed as a mosaic of quotations; any text is the absorption and transformation of another."[4] Both Chinese
Dream and American Dream, in this sense, should be considered as the unique states of the texts and the particular existences of the texts, lying in the fact that Chinese Dream and American Dream are the conscious or unconscious reflections of Chinese and American thoughts, history, realities, etc. Although Chinese nation and American nation have different cultural origins, we cannot deny such a truth that we are all human beings and human beings share dreams while the dreams may be intertextual, i.e., Chinese Dream and American Dream may characterize themselves with "mosaic of quotations", "the absorption and transformation of another", intermingling, echoing, or interweaving[4].

\section{The Background Knowledge of Chinese Dream and American Dream}

\section{A. The Background Knowledge of Chinese Dream}

Chinese people have a belief that dreams are the natural phenomena happening within human minds and they look mysterious and can represent people's psychological activities and spiritual experiences[5]. In order to approach more secrets of dreams, Chinese people ever tried explaining their dreams since ancient times. According to Wang Yi, a Chinese scholar today, Chinese Dream culture has existed for thousands of years and its dream contents are characteristic and various[6]. Definitely, if we observe the long Chinese history, "Si Gan" and "Wu Yang" of The Book of Songs should be the earliest records about Chinese people's dreams[6]. "Si Gan" contains the prediction to have a boy or a girl through seeing the dreams of a woman who is supposed to give birth soon whereas "Wu Yang" reveals the possibilities of having good fortunes or evil lucks by examining a shepherd's dream "from locusts to fish" or "from turtles and snakes to eagles". Afterwards, more Chinese records are avalable to predict dreams. Chronicle of Zuo employs dreams to foresee the consequences of battles, taking "Duke Wen of Jin dreamt of fighting with King of Chu" as an instance; Shih Chi records that dreams may mean the need of gathering talented people, taking "Wu Ding, King of Shang Dynasty, dreamt that Heaven bestows him an able man to help him govern his country" as an example. Meanwhile, Rites of Zhou even records that "dreams about the Sun, the Moon and the Stars will be the potential indications of people's future fates". Apart from these writings, dreams about death, animals, spirits, etc. are recorded in the following historical documents and files. Among Chinese literary works, the one that value much about 
dreams and firstly give philosophical meanings to dreams should be Chuang Tzu, which records that "Chuang Tzu dreams that he changed into a butterfly one day, dancing in the air happily and freely." [6] Chuang Tzu's dream is considered be immortal as Chinese people would like to talk about "Chuang Chou's Dream with a Butterfly" even today and the dream, according to certain scholars, perfectly reflects Chinese philosophy of the integrity of man and nature as well as the unity of man and the world, i.e, "Heaven, Earth and I come into being together, and all things and I are one."[7] Amazingly, since then, Chinese Dream is no longer a dream for small talks. Chinese Dream becomes the fundamental themes of the distinguished intellectuals like Qu Yuan(340BC278BC) in his Lisao, Song Yu(298BC-222BC) in his Ode to Gaotang and Ode to Goddess, Wang Yanshou(140?-165?) in his Ode to Dreams, Wang Bo(649?-675?) in his Qiuyang Miscellanies, Li Po(701-762) in his Mount Skyland Ascended in a Dream-A Song of Farewell, Chen Shiyuan(1516-1597) in his Book of Oneiromancy, Wang Zhaoyuan (1763-1851) in her Book of Dreams, etc[1,6]. Accordingly, Guo Moruo(18921978), a modern Chinese litterateur, points out that Chinese Dream has a tendency of absorbing the spirits of Buddhism, Confucianism and Daoism and later producing a special branch of Chinese philosophy in modern world[6,7]. Besides, many recognized works are also seen in the following history. The books like The Dream of the Red Mansion by Cao Xueqin(1715-1764), Journey to the West by $\mathrm{Wu}$ Chen'en(1510?-1582?), Outlaws of the Marsh by Shi Nai'an(1296-1370?), Romance of the Three Kingdoms by Luo Guanzhong(1330?-1400?), etc. are the most wonderful representatives of this field to signify the dignity of Chinese Dream in literary as well as philosophical fields. In modern China, with our ancestors' cultural glory gradually fading away and the prevailing of the western countries in international influences, Chinese Dream has new implications, which seem more realistic and down-to-earth than before. Just as $\mathrm{Xi}$ Jinping, President of China today, remarks that "To achieve the Chinese Dream is to realize the national prosperity, the national rejuvenation and the happiness of the people"[8], thus making contemporary Chinese Dream full of political and cultural tendencies.

\section{B. The Background Knowledge of American Dream}

American people, because of the unique historical environments they are faced with, have obviously distinctive dreams compared with Chinese people[9]. However, it is an incontrovertible truth that their dreams are deeply rooted in their strong beliefs of democracy, equality, freedom and fraternity and they persistently fight for their dreams through their dedicated fulfillment of individualism and independent spirits that Providence provides for them. If we initially walk back to the Colonial time of America, we can hardly witness the true American Dream because all the colonists are from European lands. If they do have some dreams, the dreams should be the colonists' dreams rather than pure American Dream. Yet we cannot ignore at least two facts here: one is that many colonists stay in America as the pioneers of the world and become the permanent citizens of America who later pass down their pioneering spirits to their offspring; the other fact is that the Puritans bring great contributions to the formation of American nation and American culture as they devotedly practice their principles of thrift, hard work, piety and sobriety in all their life. The Puritans paved the foundation for the prosperity of American Dream, both religiously and worldly. Benjamin Franklin(1706-1790), one of the Founding Fathers of the United States, deserves the honorable title of "The First American" [10] because he established the mythology of American Dream. In other words, Franklin, though born in a poor family, became the internationally famous "author, printer, political theorist, politician, postmaster, scientist, musician, inventor, satirist, civic activist, statesman, and diplomat"[11] with his personal struggles and persuaded American people to believe that any one can become successful if they work hard and any American Dream can come true if they persist in their dreams. One of the immortal dreams realized is that the Declaration of Independence was passed and the United States of America was established on July 4th, 1776 with the mutual efforts of all Americans who "hold these truths to be self-evident, that all men are created equal."'[12] Undoubtedly, the establishment of USA is historically significant and it opens a new era for all Americans who maintain American Dream. Yet the dream cannot be perfect enough because the black who sacrificed their lives in wars in exchange for their happy life were proved not really happy because they were haunted by the racial discrimination at that time, which was a nightmare that frustrated the willpower and energy of many black people. Hence, the struggle between the white and the black began. Meanwhile, American Civil War took place between 1661 and 1665 , one of the themes of the war is that the slavery system should be abolished and the black should have their human rights. Abraham Lincoln(1809-1865), the 16th President of America, issued in due course The Emancipation Proclamation, which declared the freedom of 3.1 million of the nation's slaves and announced a promising future for all Americans. However, the racial discrimination was not completely done otherwise the black intellectuals like Martin Luther King(1929-1968) would not organize 1963 March on Washington and shout "I have a dream" in public to clarify equality and democracy for all black Americans. On the way to obtain human rights, women play another unique role in the development of American democracy. "Women's movement, diverse social movement, largely based in the United States, seeking equal rights and opportunities for women in their economic activities, their personal lives, and politics...touched on every area of women's experience-including family, sexuality, and work"[13]. Of course, women's dream shares colorful contents of American Dream in its history. Literatures can be the perfect references to demonstrate the various forms of American Dream as well. If Franklin founded the American Dream through his Poor Richard's Almanack(1733-1758) and The Autobiography(1817), James Fenimore Cooper (17891851) then recorded American Pioneering Dream with his 
prominent The Leatherstocking Tales: The Pioneers(1823), The Last of the Mohicans(1826), The Prairie(1827), The Pathfinder(1840) and The Deerslayer(1841). If Walt Whitman (1819-1892) and Ralph Waldo Emerson (1803-1882) composed their Democratic and Transcendental American Dream in Leaves of Grass(1855-1891) and Nature(1836), Nathaniel Hawthorne(1804-1864) and Mark Twain(18351910) then portrayed their Romantic and Carefree American Dream in The Scarlet Letter (1850) and Tom Sawyer and Huck Finn Series(1876,1885). If Jack London (1876-1916) and Ernest Hemingway(1899-1961) declared their Willpower American Dream in The Call of the Wild(1903) and The Old Man and the Sea(1952), F. Scott Fitzgerald (1896-1940) then imagined Wealthy American Dream in The Great Gatsby(1925) while Theodore Dreiser(1871-1945) concluded the Nightmare American Dream in Sister Carrie (1900) and An American Tragedy (1925)... Whatever, American Dream is a constant theme for all Americans and penetrates almost any art area, which brings American people unbound imaginations.

\section{The Common Pursuits of Chinese Dream and American Dream}

\section{A. The Prosperity of the Nation}

Intertextually, we notice that both Chinese Dream and American Dream share the aims of prospering the nation so the dreams look holy and worthy. Observing the fivethousand-year-long Chinese history, all kings and emperors of diverse dynasties have great hopes of maintaining power and strength and think out ways to keep their kingdoms or empires thriving and prosperous. On the one hand, they possess strong desires of living immortally; on the other hand, they use their potential wisdom and capabilities to guarantee their accomplished powers not to be seized, or they will suffer the humiliation of the followers. Among the prosperous periods that make Chinese people proud for ages, Tang Dynasty is the one that attracted the attention of the world at that time. Four great inventions like gunpowder, compass, paper and printing had been made and introduced through the Silk Road, along with Chinese Confucius culture and classical art like poetry, to the Far East, the Mediterranean areas, the nearby countries like Japan and Korea, etc. to do good to the development of all human civilization... Though China was falling behind in the Contemporary World History compared with Western nations, the prosperity of Chinese land is always the central task for all Chinese leaders and Chinese people today, which we can never afford to ignore. Meanwhile, American Dream also implies that the property of the nation is a significant cause to accomplish in all periods. On the occasion when George Washington, first President of America, made his inaugural address, he put his hand on the Bible and promised that all Americans would have a "government for the security of their union and the advancement of their happiness"[14]. President Thomas Jefferson tried his best to reach his goals and he set a good model for the following presidents. So when John Quincy Adams, Abraham Lincoln, Theodore Roosevelt, etc. became American presidents, they naturally aimed at the prosperity of the nation and held it as a significant job to fulfil. Especially in two world wars, when the old capitalist countries like Britain, Germany, France, etc. gradually lost their dominant influences, America chose a wise position to achieve the most abundant wealth thus becoming the most powerful country today though its history is merely about 300 years. America has no other choice, as American Dream tends to tell.

\section{B. The Happiness of the People}

To know how prosperous a nation is, one of the most important references is to observe how happy the people are in the nation. This is true not only for China but also for America. Initially, the happiness of the people is proved to be a valuable theme in Chinese history. If Chinese people were not satisfied with their living conditions or they were much oppressed by the governors, they would rise up, revolt or fight against the governors' ill-management. Perhaps that is one reason why China experienced about 25 dynasties in different periods. Chinese people have a folk saying, "Kings and Emperors are like the boats while the people are like the water below. The water can carry the boats away and of course can throw them away." The fact implies that it is a great Chinese Dream to feed all Chinese people well and make sure all of them can live happily though it is a challenging task to finish. Today, the dream of feeding 13 billion people has been realized, and the next dream is to make their life much better and happier. Chinese government is carefully observing this and trying to make all possible means to meet the needs of people. By comparison, the happiness of the people is also a wonderful American Dream. Though Americans have different definitions for their happiness, the routine life like eating well, working well, living well, etc. proves to be the same important tasks they have to focus on as Chinese people do in their life. Yet they may have particular references. American people have the inclinations of taking their basic human rights like democracy, freedom, equality, etc. as the principles to evaluate the success of the government. They also cheer for individualism and heroism. Thus their dreams would contain Americanized styles and spiritual contents, which require both American people and American government to practice unique measures to maintain and satisfy.

\section{The Harmony of the Society}

Harmony is an issue that both Chinese Dream and American Dream care about. Actually in very ancient time, Chinese people had already expressed their understanding about harmony. Harmony, as Confucius concluded, may refer to the perfect ensemble of the musical instruments which combine the styles of different chords and tunes to show a focused subject. Based on this, harmony is used to refer to the good relationship between people afterwards. According to Lao Tzi and his Taoism, harmony means the good relationship between man and nature, man and man, and man and society. Accordingly, the thought of harmony gradually mingles with Chinese culture, art and religion and becomes an indispensable part of Chinese spirit. Nowadays, in China, harmonious society concerns two aspects: the harmonious social 
relationship as well as the harmonious natural relationship. The former reveals that all people should do their best, enjoy their proper places and share all that they have achieved in harmony while the latter implies that when we develop our society, we cannot ignore the importance of nature and do harm to nature because nature is a part of human ecological system. American society will also have to find ways to make its social and natural environment harmonious. On the one hand, even if America occupies the most powerful economic position in the world, it does not mean that all American people live harmoniously. On the other hand, America is still a country with unbalanced ecological systems that may result in various pollutions. As for all these poor situations, American government finds no way out till now, which makes American people full of complaints. So, if America wants to realize its world of universal harmony, there is still a long way to go; if American Dream wants to come true earlier, there is still much work to accomplish.

\section{The Peace of the World}

The eagerness for the peace of the world and the very pursuit of it are the constant objectives that Chinese people strive for in the past as well as today. Chinese people will never forget the awful consequences that the wars brought about to them as well as the troubles the natural disasters caused to them. The endless feud between ethic groups and the revengeful murdering between countries only result in meaningless losses and deaths at both sides. Hence, the various unpleasant experiences make Chinese people aware of such a fact that the peace of the world is important because the peaceful environment not only brings them the life support, but also offers them the wonderful atmosphere to leverage their wisdom and capacities to create a better world. Without the peace of the world, without the hopes of happiness. As for all Chinese, peace of the world is not a simple dream to bear in mind, but a valuable target to fulfill till success. Intertextually, America also has its responsibility to keep the peace of the world. America is the strongest country in the world, yet it is also the easiest country to be found to attack because America is the most shining object to notice and aim. The lessons of 9.11 warn Americans that dangers may exist all around and keeping the peaceful environment allows of no delay. Although America seems never to be afraid of any threat because it owns the most advanced nuclear weapons and the most efficient aircraft carriers, once the war is going on, any "invincible legend" would be destroyed. So to speak, only in the peaceful environment, America can be called the most advanced or the most powerful. Naturally, the peace of world will be an important American Dream.

\section{Summary}

In brief, Chinese Dream and American Dream are intertextual because they are two unique texts that share the features of intertextuality, as what Julia Kristeva ever claimed. Chinese Dream and American Dream have different backgrounds, yet their backgrounds reveal transparently that the two dreams are deeply rooted in their own respective traditions and cultures which characterize themselves with intertextual traces. Additionally, we can find the evidences of demonstrating that the two dreams are actually intertextual by referring to their common pursuits for the prosperity of the nation, the happiness of the people, the harmony of the society and the peace of the world. Besides the discussion above, we may draw another two conclusions here, one is that the intertextual features of Chinese Dream and American Dream have been ignored for long and their intertextual relationship needs our attention and more argumentation; secondly, as the particular existences of intertextuality, Chinese Dream and American Dream have undiscovered research focuses, either macroscopic or microscopic, diachronic or synchronic. Therefore, we need further studies about their intertextual relationship.

\section{Acknowledgment}

The research described in this paper is financially supported by the research programs sponsored by Shaanxi Social Science Association(2013Z092); Shaanxi Social Science Fund(08K005); Ministry of Education of China(GPA105004, 10YJA752031); the Innovation Funds of Graduate Programs(2013CXB013), SNNU; 2013 Visiting Scholar Exchange Program(P-1-04989), SNNU; and SNNU Elementary Education Curriculum Research Center of Ministry of Education of China(JCJY201318).

\section{References}

[1] F. Wang, "American literature and American dream," Journal of Inner Mongolia University, vol. 34, no. 2, pp. 40-43, March 2002.

[2] Wikipedia, "Sigmund Freud," Information on http://en.wikipedia.org/wiki/Freud, 2013-09-18.

[3] M. Octave, Freud: The Theory of the Unconscious, London: NLB, 1971, pp. 146-47.

[4] J. Kristeva, "Word, dialogue and novel," in The Kristeva Reader, Toril moi ed., Oxford: Blackwell Publisher Ltd., 1986, pp. 36-37.

[5] D. Y. Yue, "American dream, European dream and Chinese dream," Social Sciences, vol. 32, no. 9, pp. 159-165, September 2007.

[6] Y. Wang, "Chinese dream culture and dream lyrics of Ming and Qing Dynasties," Chinese Literature Studies, no. 4, pp. 29-36, August 1993.

[7] $\mathrm{Z}$. Li, "The being of all things," Information on http://artsilk.blog.hexun.com/26961699_d.html, 2008-12-14.

[8] Y. Huang and Q. A. Sun, "The dimensional scene of 'Chinese Dream': national rejuvenation," School Party Construction and Ideology Education, vol. 38, no. 10, pp. 12-14, October 2013.

[9] W. Yan and G. P. Shen, "The emergence, development and disillusionment of American dream," Journal of Xichang Teachers College, vol. 15, no. 2, pp. 34-37, June 2003.

[10] H.W. Brands, the First American: The Life and Times of Benjamin Franklin, New York: Doubleday, 2000, pp. 3-15.

[11] Wikipedia, "Benjamin Franklin," Information on http://en.wikipedia.org/wiki/Benjamin_Franklin\#cite_note-4,2013-09-21.

[12] American Congress, "Declaration of Independence," Information on http://www.earlyamerica.com/earlyamerica/freedom/doi/text.html.

[13] E. Burkett, "Women's movement," Information on http://www.britannica.com/EBchecked/topic/647122/womens-movement

[14] G. Washington, "First inaugural address in the City of New York," Information on http://www.bartleby.com/124/pres13.html, 1789-04-30. 